\title{
The Game Research of the Public Crisis Prevention
}

\author{
Miangui Cheng ${ }^{1}$ \\ PH.D. \\ Northwestern Poly-technology University \\ Xian, Shaanxi, China
}

\begin{abstract}
The disposal of public crisis prevention problem was researched, and we established the game model between local government and inspection department. From the point of profit maximization, the operation efficiency of local government and inspection department was analyzed. Through the results, got from the model, some advices were proposed to guide the improvement of public crisis.
\end{abstract}

Keywords- Game model; Public crisis management; Inspector

\section{INTRODUCTION}

Crisis prevention and management of preparedness and response is "the idea that, raising, training and the use of troops" relationship, in the preparation phase, training, advocacy, research and training plan is a major task, however, based on the work of all of these specialized management agencies as the Government's failings missing. Government crisis management subjects, including central and local governments, specific and can be divided into the Central Government, the various functional departments, local government, local government functions. When limited to incidents in parts of the hazards, the main manager was higher governments and relevant departments in the region; when unexpected events spread throughout the country, spread to all areas, the management also extends to the main central government and central ministries. Government organizations are not only representatives of public interest, is also represents the interests of its members, when the personal interests of the public interest consistent with the officials, the officials consciously strive to achieve the public interest; when the public interest and government officials are inconsistent and even conflicting interests when, self-motivation may lead officials to deviate from the public interest. To achieve personal interest in this game is individual rationality, collective rationality to achieve the public interest, and potentially the individual rationality may lead to collective irrationality. In a sense, the crisis prevention and management of the process, government departments and between the upper and lower levels of Right and Interest in the distribution and the corresponding incentive mechanism is maximized. As driven by short-term interests, some government departments will not choose to crisis prevention and control input to short-term profits. Therefore, the Government sector in crisis prevention and management duties and responsibilities can also be included in the areas of game theory to study.

\section{LITERATURE REVIEW}

My academic research in this area started late, although not as some scholars say - "China Crisis and Crisis Management currently at the initial stage of crisis and crisis management research involves mostly quite broad theory, Almost without exception, they do not study China experienced crisis and crisis management "[1], but there are obvious deficiencies, mainly in a large number of published qualitative research, quantitative research serious shortage of $[2,3]$.

Game theory originated in the beginning of this century, in 1994 von Neumann and Morgenstern - co-author of "Game Theory and Economic Behavior," laid the theoretical foundation of game theory. Since the 50s of the 20th century, some scholars, such as Nash, Selten, Harsanyi, and others to make the final maturity of game theory into practical. The past 20 years, game theory as the analysis and resolution of conflict and cooperation tools, in the management of science, international politics, ecology and other fields is widely applied [4,5]. This article will apply game theory to the local government's crisis prevention and supervision work will model the study efficiency.

\section{MODEL TO DESCRIBE THE PROBLEM}

Suppose a collection of participants $N=\{1,2\}$, including a department that is responsible for crisis prevention or management of local governments in some areas (for there is no dedicated area of crisis prevention), 2 said the higher charge of crisis prevention progress, state inspectors sector. The type of space $\varphi=\left\{T_{y}, T_{n}\right\}$ for local government, ${ }^{T}$ which said that local governments deal with serious and responsible work in crisis prevention and positive for crisis prevention; $T_{n}$ that local governments work in crisis prevention irresponsible, negative response to the crisis prevention. $T_{i}$ The local government's private information, only local governments are aware of their type $T_{y}$ or belonging to $T_{n}$, the supervision department of the higher authorities only know the probability distribution: $P\left(T=T_{y}\right)=q_{;} P\left(T=T_{n}\right)=1-q$. Suppose the local 
government to prevent the cost of active is ${ }^{C} p_{p}$ and passive prevention cost is 0 .

Space operations $A_{1}=\left\{a_{11}, a_{12}\right\}, a_{11}$ said the local government, which said the local government of its intention to crisis prevention work carried out to conceal the situation, so that in a crisis if there is slack in the prevention of the situation will be difficult to detect; $a_{12}$ that local governments interested in working condition for its crisis prevention and not to hide, if it exists in crisis prevention slack condition part of inspector would easily be found.

The supervision department $A_{2}=\left\{a_{21}, a_{22}\right\}$, $a_{21}$ said the action space, in which inspectors said the crisis in local government departments actively working conditions to prevent scrutiny will be on the local government's crisis management will have a clearer understanding, even if the local government sector working conditions of its crisis prevention to hide their true working status can also check out, cause this way in checking the check cost is $c_{21}, c_{21}>0 ; a_{22}$ said the supervision of the local government of crisis prevention status be negative for check out, now local government if crisis prevention work conceal conditions, then the oversight is difficult to find work in crisis prevention slack exists in the situation, this way of checking the inspection costs caused by $C_{22}, C_{22} \geq 0$, assuming $C_{21>} C_{22} \geq 0$ that the positive check inspection costs arising from higher than the cost of a negative check .

If the inspection found that local governments work in their crisis prevention the situation there is a negative response and will require the additional cost ${ }^{c_{p}}$ of retention of crisis prevention, crisis prevention if both the local government for its work to conceal the negative response to the issue, part of the inspectors a false report, will have to give the corresponding administrative penalty $P$. Crisis prevention work to discover the problems local government inspectors departments will receive awards, assuming reward amount $E$.

\section{CHARACTERIZATION}

First introduced by the conversion Hai Sani Virtual Human Nature select the type of local government $[6,7], \pi_{1}$ that the local government's revenue function,

$\pi_{2}$ that oversight of the revenue function.

When natural selection the type of local government is $T_{y}$ :

If local governments choose to conceal their acts of crisis prevention works $a_{11}$, if the supervision department of the decision-making at this time to work on the local crisis prevention strict inspection $a_{21}$ and supervision department of the local government revenue function, $\pi_{1} \quad \pi_{2}$ respectively. $\pi_{1}\left(T_{y}, a_{11}, a_{21}\right)=-c_{p} \quad$ And $\pi_{2}\left(T_{y}, a_{11}, a_{21}\right)=-c_{21}$

If the inspectors of the local government sector decision-making for the prevention of negative inspection crisis, the local government revenue remains unchanged, the revenue department inspectors function $\pi_{2}, \pi_{2}\left(T_{y}, a_{11}, a_{22}\right)=-C_{22}$.

If local governments choose not to their crisis prevention efforts to conceal $a_{12}$, their revenue function from inspectors sector decision-making influence, $\pi_{1}\left(T_{y}, a_{11}, a_{21}\right)=-c_{p}$, The strict or lax inspection mode inspectors sector earnings function were $\quad \pi_{2}\left(T_{y}, a_{11}, a_{21}\right)=-c_{21}$ $\pi_{2}\left(T_{y}, a_{11}, a_{22}\right)=-c_{22}$.

When natural selection the type of local government is $T_{n}$ :

If local governments choose to hide their acts of crisis prevention and supervision department of the decisionmaking at this time to work on the local crisis prevention strict inspection and supervision department of the local government revenue function, $\pi_{1} \pi_{2}$ respectively was $\quad \pi_{1}\left(T_{n}, a_{11}, a_{21}\right)=-P-c_{p}$; $\pi_{2}\left(T_{n}, a_{11}, a_{21}\right)=E-c_{21}$

If local governments choose to conceal their crisis prevention work $a_{11}$, check the inspectors departments to take a negative $a_{22}$, then the local governments and departments of the revenue function inspectors were $\pi_{1}$ $\pi_{2}: \pi_{1}\left(T_{n}, a_{11}, a_{22}\right)=0 ; \pi_{2}\left(T_{n}, a_{11}, a_{22}\right)=-c_{22}$

If local governments choose not to hide their work in

crisis prevention $a_{12}$ and supervision department of the decision-making on crisis prevention work to strict inspection $a_{21}$ and supervision department of the local government's revenue function, $\pi_{1} \pi_{2}$ respectively was $\pi_{1}\left(T_{n}, a_{11}, a_{22}\right)=-c_{p} ; \pi_{2}\left(T_{n}, a_{11}, a_{22}\right)=E-c_{21}$

If local governments choose not to hide their work in crisis prevention $a_{12}$ and supervision department of the decision-making on crisis prevention work to strict inspection $a_{22}$ and supervision department of the local government's revenue function, $\pi_{1} \pi_{2}$ respectively was 
$\pi_{1}\left(T_{n}, a_{11}, a_{22}\right)=-C_{p} ; \pi_{2}\left(T_{n}, a_{11}, a_{22}\right)=E-c_{22}$

The following sections will be Game of the possible strategies of both sides to analyze possible strategies for the separation of local government strategies:

$$
a_{1 i}= \begin{cases}a_{11} & T=T_{y} \\ a_{12} & T=T_{n}\end{cases}
$$

Caused by the separation strategy separating equilibrium is such a balance: gamer select different in different types of action.

The second strategy is confused with strategy

$$
a_{1 i}=a_{11} \quad T=T_{n}, T_{y}
$$

Pooling strategy is gamer always choose the same action. In a pooling equilibrium in gamer balance in the observed action does not update his belief after the $[8,9]$.

In the first, when $a_{1 i}=a_{11}$, and supervision department of the local government crisis management work is estimated at $p\left(T=T_{y} \mid a_{11}\right)=1$ $p\left(T=T_{n} \mid a_{11}\right)=0$.

If $a_{1 i}=a_{12}$, supervision departments of local government crisis management work is estimated at $p\left(T=T_{n} \mid a_{1 i}=a_{12}\right)=1, p\left(T=T_{y} \mid a_{1 i}=a_{12}\right)=0$.

Inspector sector objective function is: $\max _{a_{2 i}} \sum \pi_{2}\left(T_{j}, a_{1 k}, a_{2 l}\right) p\left(T_{j} \mid a_{1 k}\right)$

When the local government does not hide its crisis prevention $a_{1 i}=a_{12}$, inspector's sector objective function is:

$$
\begin{aligned}
& \max _{a_{21}} \sum \pi_{2}\left(T_{j}, a_{1 k}, a_{21}\right) p\left(T_{j} \mid a_{1 k}\right) \\
& =\max _{a_{2 i}}\left\{\pi_{2}\left(T_{y}, a_{12}, a_{21}\right) p\left(T_{y} \mid a_{12}\right)+\pi_{2}\left(T_{n}, a_{12}, a_{21}\right) p\left(T_{n} \mid a_{12}\right)\right\} \\
& =\max _{a_{2 i}}\left\{\pi_{2}\left(T_{y}, a_{12}, a_{21}\right) p\left(T_{y} \mid a_{11}\right)+\pi_{2}\left(T_{n}, a_{12}, a_{21}\right) p\left(T_{n} \mid a_{12}\right)\right\} \\
& =\max \left\{\pi_{2}\left(T_{n}, a_{12}, a_{21}\right), \quad \pi_{2}\left(T_{n}, a_{12}, a_{22}\right)\right\} \\
& =\max \left\{-c_{21}+E, E-c_{22}\right\} \\
& =E-c_{22} \\
& \quad \operatorname{Then,} \\
& \max _{a_{2 i}} \sum \pi_{2}\left(T_{j}, a_{12}, a_{2 l}\right) p\left(T_{j} \mid a_{12}\right)=-E-C_{22} \text {, that }
\end{aligned}
$$

the optimal strategy at this time oversight for the positive check, $a_{2 i}^{*}\left(a_{12}\right)=a_{22}$.

When the local government to conceal its crisis prevention, then $a_{1 i}=a_{11}$, department inspectors at this time the objective function is: $\max _{a_{2 i}} \sum \pi_{2}\left(T_{j}, a_{11}, a_{2 l}\right) p\left(T_{j} \mid a_{11}\right)=-c_{22}$
Then if the local government strategy $\left(a_{12}, a_{11}\right)$, the Inspector sector strategy $\left(a_{22}, a_{21}\right)$, that is, the optimal strategy at this time oversight for the negative examination.

When the Inspector departments over inspection strategy, the local government's objectives $\max \left(\pi_{1}\left(T_{j}, a_{1 i}, a_{22}\right)\right)$, its strategy is as follows:

$$
\begin{aligned}
& \text { When the local government type was } \\
& \quad \max _{a_{1 i}} \pi_{1}\left(T_{n}, a_{1 i}, a_{2}^{*}\right) \\
& =\max _{a_{1 i}}\left\{\pi_{1}\left(T_{n}, a_{11}, a_{22}\right), \pi_{1}\left(T_{n}, a_{12}, a_{22}\right)\right\} \\
& =\max \left\{\pi_{1}\left(T_{n}, a_{12}, a_{22}\right), 0\right\} \\
& =-P-c_{p}
\end{aligned}
$$

When the local government type was $T_{y}$

$$
\begin{aligned}
& \max _{a_{1 i}} \pi_{1}\left(T_{y}, a_{1 i}, a_{2}^{*}\right) \\
& =\max _{a_{1 i}}\left\{\pi_{1}\left(T_{y}, a_{11}, a_{21}\right), \pi_{1}\left(T_{y}, a_{12}, a_{22}\right)\right\} \\
& =\pi_{1}\left(T_{y}, a_{11}, a_{22}\right)
\end{aligned}
$$

That the optimal strategy for the local government was $a_{1}^{*}(T)=\left(a_{11}, a_{11}\right)$

The following discussion of 2 , regardless of whether the work of local government there is slack in crisis prevention, which do not conceal the situation of the supervision department, $a_{1 i}=a_{11}, T=T_{n}, T_{y}$

At this point the work of supervision departments of the local types of Bayesian estimation as:

$$
\begin{array}{ll}
p\left(T_{y} \mid a_{11}\right)=q ; & p\left(T_{n} \mid a_{11}\right)=1-q \\
p\left(T_{y} \mid a_{12}\right)=0 ; & p\left(T_{n} \mid a_{12}\right)=1
\end{array}
$$

When the local government's strategy $a_{11}$, inspector's sector revenue functions as:

$$
\begin{aligned}
& \max _{a_{2 i}} \sum \pi_{2}\left(T_{j}, a_{11}, a_{2 l}\right) p\left(T_{j} \mid a_{11}\right) \\
& =\max _{a_{2 i}}\left\{\pi_{2}\left(T_{y}, a_{11}, a_{2 l}\right) q+\pi_{2}\left(T_{n}, a_{11}, a_{2 l}\right)(1-q)\right\} \\
& =\max _{a_{2 i}}\left\{-c_{21} q+\left(E-c_{21}\right)(1-q),-c_{22} q-c_{22}(1-q)\right\} \\
& =\max \left\{-c_{21}+(1-q) E,-c_{22}\right\} \\
& \quad \text { Supposed } E-c_{21}-q E>-c_{22} \\
& \quad \text { Then } \\
& \max _{a_{2 i}} \sum \pi_{2}\left(T_{j}, a_{11}, a_{2 l}\right) p\left(T_{j} \mid a_{11}\right)=-c_{21}+(1-q) E
\end{aligned}
$$

Inspector sector strategy was $a_{21}$. 
When the local government strategy $a_{12}$, inspector's sector revenue functions as:

$$
\begin{aligned}
& \max _{a_{2 i}} \sum \pi_{2}\left(T_{j}, a_{12}, a_{2 l}\right) p\left(T_{j} \mid a_{21}\right) \\
& =\max _{a_{2 i}}\left\{\pi_{2}\left(T_{n}, a_{12}, a_{2 l}\right)\right\} \\
& =\max _{a_{2 i}}\left\{\pi_{2}\left(T_{n}, a_{12}, a_{21}\right), \pi_{2}\left(T_{n}, a_{12}, a_{22}\right)\right\} \\
& =\max _{21}\left\{-c_{21}+E,-c_{22}+E\right\} \\
& =-c_{22}+E \\
& \text { So } a_{2 k}^{*}\left(a_{12}\right)=a_{22}
\end{aligned}
$$

When the inspector sector strategies is $\left(a_{22}, a_{21}\right)$, local function $a_{2 i}$

$$
\max _{a_{2 i}} \sum \pi_{1}\left(T_{j}, a_{1 i}, a_{2 k}^{*}\right) \text {. }
$$
objective

$$
\begin{aligned}
& \text { When } T=T_{n} \\
& \quad \max _{a_{1 i}} \pi_{1}\left(T_{n}, a_{1 i}, a_{2}^{*}\right) \\
& =\max _{a_{1 i}}\left\{\pi_{1}\left(T_{n}, a_{11}, a_{21}\right), \pi_{1}\left(T_{n}, a_{12}, a_{22}\right)\right\} \\
& =\max \left\{\pi_{1}\left(T_{n}, a_{12}, a_{22}\right), 0\right\} \\
& \text { So } a_{1 i}^{*}\left(T_{n}\right)=a_{12} \\
& \text { When } T=T_{y} \\
& \quad \max _{a_{1 i}} \pi_{1}\left(T_{y}, a_{1 i}, a_{2}^{*}\right) \\
& =\max _{a_{1 i}}\left\{\pi_{1}\left(T_{y}, a_{11}, a_{21}\right), \pi_{1}\left(T_{y}, a_{12}, a_{22}\right)\right\} \\
& =\pi_{1}\left(T_{y}, a_{11}, a_{21}\right) \\
& \text { So } a_{1 i}^{*}\left(T_{n}\right)=a_{11}
\end{aligned}
$$

Inspector sector strategy $\left(a_{22}, a_{21}\right)$ led to the local government strategy $\left(a_{12}, a_{11}\right)$. So in the end local government and departments will alternate inspector's separation strategy and confused strategy.

When $E-c_{21}-q E<-c_{22}$, similar we can prove that the game was balanced as the model $\left[\left(a_{11}, a_{11}\right),\left(a_{22}, a_{22}\right)\right]$.

\section{CONCLUSION}

The nature of the model can be drawn, on the one hand incentives for risk management inspector must have a certain strength, or will fall short of hard work to stimulate the effect of inspectors, inspection departments will be difficult to guarantee the local government's crisis management work careful monitoring of active and effective. On the other hand, the crisis management by local governments to conceal their work in their state without any cost cases, the working conditions through the way to hide and escape crisis prevention task, therefore people should consider setting up a report and networks, and many direct communication tool, allowing local governments to hide the high cost of their work, thus abandoning the negative attitude of responsibility.

\section{REFERENCES}

[1] Tang Jun. Of public crisis management: international developments and experiences in construction [J]. New Vision, 2003,6

[2] Glucose deprivation in the basic characteristics of public crisis management and systematic construction, East China Economic Management, No. 3, 2004

[3] He Zhiwu, Jia Rong governance, the Government Crisis Management, Academic Forum, No. 1, 2004

[4] J. Harsanyi. Games with Incomplete Information Played by Bayesian Players[J].

Management Science, 1997,14:159-82,320-34, 486-502

[5] Grateful to know. Game Theory [M]. Shanghai: Fudan University Press, 1997,45

[6] JOFRE-BONET, M., M. PESENDORFER. Estimation of a Dynamic Auction

Game[J]. Econometrica, 2003, 71:1443-1489.

[7] Pearce D.G., Stacchetti E.. The interaction of implicit and explicit contracts in

repeated agency[J]. Games and Economic Behavior. 2005, 23(01):75-96

[8] The king of jade. Fighting Honesty game model [J]. Henan University of Technology, 2001, (4)

[9] Zheng Liping • Economic Analysis of Corruption [M] • Beijing: Central Party School Press, 2000. 